\title{
Difficult Intubation in a Patient with Dysphagia after Posterior Occipitocervical Fusion: A Case Report
}

\author{
Junichi Nishiyama, Aki Ando, Tomohiko Murata, Mariko Watanabe, Hajime Yamazaki, \\ Satoru Saito, Toshiyasu Suzuki
}

Department of Anesthesiology, Tokai University School of Medicine, Isehara, Japan

Email: j-nsym@is.icc.u-tokai.ac.jp

How to cite this paper: Nishiyama, J., Ando, A., Murata, T., Watanabe, M., Yamazaki, H., Saito, S. and Suzuki, T. (2017) Difficult Intubation in a Patient with Dysphagia after Posterior Occipitocervical Fusion: A Case Report. Open Journal of Anesthesiology, 7, 121-129.

https://doi.org/10.4236/ojanes.2017.75012

Received: April 5, 2017

Accepted: May 21, 2017

Published: May 24, 2017

Copyright (c) 2017 by authors and Scientific Research Publishing Inc. This work is licensed under the Creative Commons Attribution International License (CC BY 4.0).

http://creativecommons.org/licenses/by/4.0/

(c) (i) Open Access

\begin{abstract}
The authors encountered a case involving difficult intubation during anesthesia for revision of cervical fixation angle in a 62-year-old woman, with a history of chronic rheumatoid arthritis, who experienced dysphagia after initial posterior occipitocervical fusion to correct atlantoaxial subluxation. Two days after initial surgery, she developed trismus with neck flexion and dysphagia, and underwent revision surgery. General anesthesia was planned; however, tracheal intubation using the McGrath laryngoscope and bronchofiberscope was difficult, which prolonged anesthesia induction. Narrowing of the oral and pharyngeal cavities associated with overcorrection of the cervical spine was believed to be the reason for difficulty in manipulating the tracheal intubation devices. In posterior occipitocervical fusion, intraoperative evaluation of the occipito-second cervical vertebra (O-C2) angle is reported to be useful in preventing postoperative dyspnea and/or dysphagia, and avoids the need for revision of fixation angle. However, when revision surgery is needed, selection of airway management methods and tracheal intubation devices are important considerations because patients are likely to have restricted mobility in the cervical spine and narrowing of the oral and pharyngeal cavities.
\end{abstract}

\section{Keywords}

Occipitocervical Fusion, Postoperative Dysphagia, Difficult Intubation, O-C2 Angle

\section{Introduction}

Postoperative complications in cervical spine surgery include dyspnea and dysphagia, in addition to bleeding, infection, and bone union failure. Patients un- 
dergoing cervical fusion are at risk for developing dyspnea and/or dysphagia because of narrowing of the oral and pharyngeal cavities due to hematoma or inflammation. The complication is particularly associated with an anterior approach [1] [2] [3] [4] [5]. In contrast, it is cautioned that patients undergoing a posterior approach are at risk for airway obstruction at the time of anesthesia and immediately after extubation, and subsequent difficulties with re-intubation [1] [6] [7]. Here, we report a case involving difficult intubation in a patient who developed trismus and dysphagia several days after posterior occipitocervical fusion and required revision surgery. Comprehensive, informed written consent was obtained preoperatively from the patient and the family (spouse) for publication of this case report; oral informed consent was obtained postoperatively.

\section{Case Report}

The patient was a 62-year-old woman (height $154 \mathrm{~cm}$, weight $53 \mathrm{~kg}$ ) with a medical history that included chronic rheumatoid arthritis (RA, diagnosed at 37 years of age). The patient visited us with the chief complaints of walking disturbance and numbness in the upper extremities and presented with instability in the neck. Magnetic resonance imaging revealed narrowing of the intervertebral disc spaces in the upper cervical spine and increased atlanto-dental interval (Figure 1). The patient was prepared for posterior occipitocervical fusion surgery because of the diagnosis of atlantoaxial subluxation. Preoperative respiratory and circulatory function and blood test results were unremarkable.

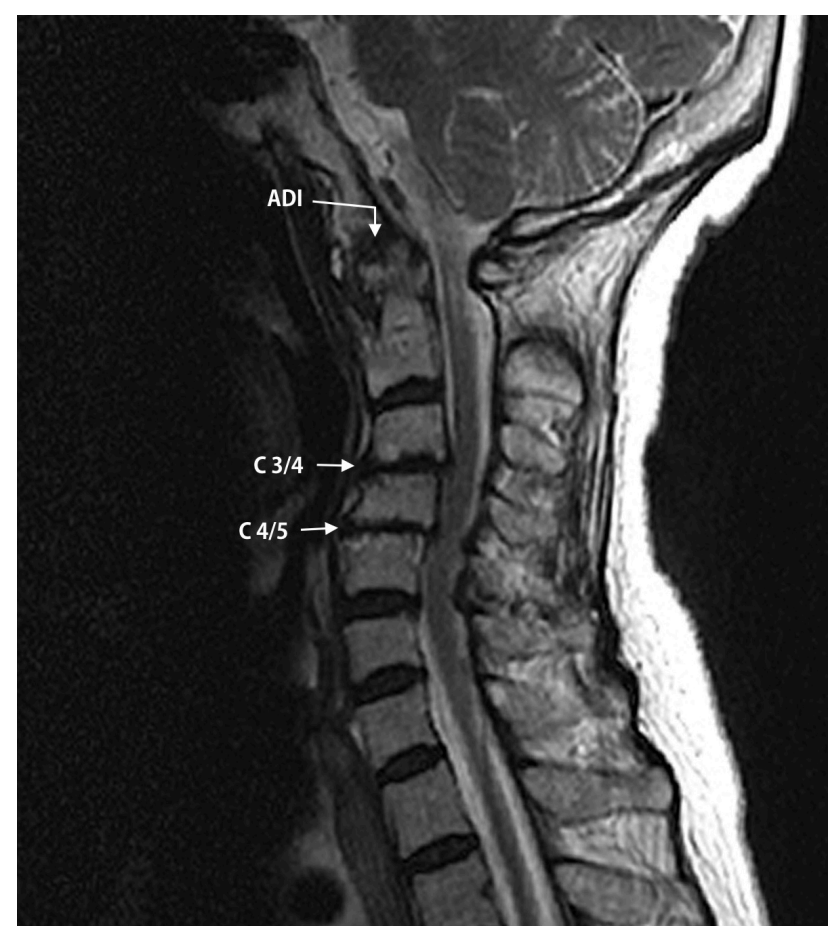

Figure 1. Lateral magnetic resonance images of the cervical spine acquired preoperatively revealed narrowing of the intervertebral disc spaces at $\mathrm{C} 3 / 4$ and $\mathrm{C} 4 / 5$, an atlanto-dental interval (ADI) of $10 \mathrm{~mm}$. 


\section{Clinical Course}

Posterior occipitocervical fusion was performed under general anesthesia. The procedure was completed without adverse events during anesthesia and surgery. The durations of surgery and anesthesia were $2 \mathrm{~h} 27 \mathrm{~min}$ and $3 \mathrm{~h} 33 \mathrm{~min}$, respectively. Extubation was performed in the operating room without problems. However, 2 days after surgery, the patient complained of difficulty with oral intake of food, and presented with trismus and dysphagia, probably due to neck flexion, for which revision of the fixation angle was planned. There was no sensation of dyspnea or symptoms of airway obstruction.

Revision surgery was scheduled to be performed one week after the initial surgery. From clinical observation of the patient, it was predicted that airway management would be difficult. Examination before revision surgery revealed a maximum inter-incisor distance of $17 \mathrm{~mm}$ (Mallampati class IV), a thyromental distance of 1.5 finger widths $(25 \mathrm{~mm})$, and lack of mobility in the neck. However, oral intubation using AWS; airway scope (PENTAX/HOYA Corporation, Tokyo, Japan.) or McGrath ${ }^{\mathrm{TM}}$ laryngoscope (Medtromic, Minnesota, U.S.) were planned after induction of general anesthesia, considering that intubation had been easily performed by avoiding neck extension using AWS under manual in-line stabilization (MILS) at the time of initial surgery, and that the patient was very anxious about being intubated while in a conscious state.

At revision surgery, it was confirmed that the McGrath blade (size 3) could be inserted in the oral cavity before induction of general anesthesia. It was not possible to insert the Intlock blade of the AWS because of limited mouth opening. After oxygenation, anesthesia was induced using propofol, and muscle relaxation was achieved using rocuronium after confirming that mask ventilation was possible using the jaw lift method. Tracheal intubation was attempted using the McGrath laryngoscope; however, the operator encountered strong resistance when inserting the blade to two-thirds of its length, and could not insert it sufficiently to obtain a good visual field of the laryngeal anatomy. Tracheal intubation using a bronchofiberscope was attempted immediately; however, it was difficult to obtain a good visual field via a transnasal approach because of severe mucosal edema extending from the nasal cavity to the upper pharynx. After switching to an oral approach, the glottis was easily visualized; however, the fiberscope was bent upward at a sharp angle, and repeated attempts to perform tracheal intubation resulted in insertion of the fiberscope tip into the esophagus. Finally, tracheal intubation was achieved by switching to a fiberscope with a larger diameter (from $3.1 \mathrm{~mm}$ to $5.1 \mathrm{~mm}$ ). The time required for successful tracheal intubation was approximately $36 \mathrm{~min}$.

At surgery, the implant was removed, and the cervical angle that had been fixed in a flexed position was corrected, and refixation was performed (surgical time was $1 \mathrm{~h}$ : $1 \mathrm{~min}$; anesthesia time was $2 \mathrm{~h}$ : $37 \mathrm{~min}$ ). After surgery, the patient remained intubated and was transferred to the intensive care unit. The next day, extubation was performed after confirming that the patient was conscious and exhibited no pharyngolaryngeal edema. The dysphagia disappeared and the de- 
gree of mouth opening improved (to approximately $3 \mathrm{~cm}$ ). Two days after surgery, the patient was transferred to a general ward and discharged from hospital 15 days later.

\section{Discussion}

Dyspnea and/or dysphagia after cervical spinal surgery are important complications: they not only affect patients' activities of daily life but also can be life threatening. Although the exact causes remain unclear, it is reported that dyspnea and/or dysphagia frequently occur in patients undergoing anterior cervical fusion, which is associated with hematoma, inflammation, pharyngeal mucosal edema, enlarged tongue, focal neurological deficits, raised palate, and severe pain [1] [2] [3] [4] [5]. In contrast, postoperative dyspnea and/or dysphagia in patients undergoing posterior cervical fusion, similar to the posterior occipitocervical fusion described in the present case, are considered to be caused by mechanical narrowing of the oral and pharyngeal spaces due to overcorrection at the time of surgery [1] [6] [7].

In recent years, the significant association between reduction in the $\mathrm{O}-\mathrm{C} 2$ angle (i.e., the angle between McGregor's line [the line connecting the posterior margin of the hard palate and the lowest point of the occipital bone] and inferior endplate of the axis [C2] in the sagittal plane of the head and neck [the front opening angle is positive] [8]) and occurrence of dyspnea and/or dysphagia in patients undergoing posterior occipitocervical fusion has attracted attention in the field of orthopedics [1] [8]. Miyata et al. retrospectively examined 29 patients who had undergone occipitocervical fusion between 2003 and 2008 and found a linear correlation of the difference between pre- and post-operative O-C2 angle with the percentage change between pre- and post-operative cross-sectional area of the oropharynx (Spearman $\mathrm{r}=0.49, \mathrm{n}=29, \mathrm{P}=0.0068$ ); the authors also reported that all patients with a difference in the O-C2 angle $<-10^{\circ}(\mathrm{n}=5)$ showed a percentage change in the cross-sectional area of the oropharynx $<-40 \%$ and developed postoperative dyspnea and/or dysphagia, whereas none of the patients without a decrease in the O-C2 angle developed these complications [8]. In the present case, the $\mathrm{O}-\mathrm{C} 2$ angle had decreased by $19^{\circ}$ after the initial surgery, suggesting that the oral and pharyngeal space at the time of revision surgery was somewhat narrow (Figure 2). Unlike dyspnea and/or dysphagia following an anterior approach to the cervical spine, dyspnea and/or dysphagia following a posterior approach are not strongly associated with inflammation, edema or neuropathy, and spontaneous recovery is not unlikely to occur in almost all cases; therefore, revision for correction of the fixation angle is necessary [1] [9] [10]. It is generally recognized that tracheal intubation using the Macintosh laryngoscope is difficult in patients undergoing cervical fusion, and a variety of tracheal intubation devices have been used in anesthesia management. In the present case, we could not insert the McGrath laryngoscope sufficiently deep to secure a visual field of the laryngeal anatomy at the time of tracheal intubation for revision surgery, and it took relatively a long time to introduce the broncho- 


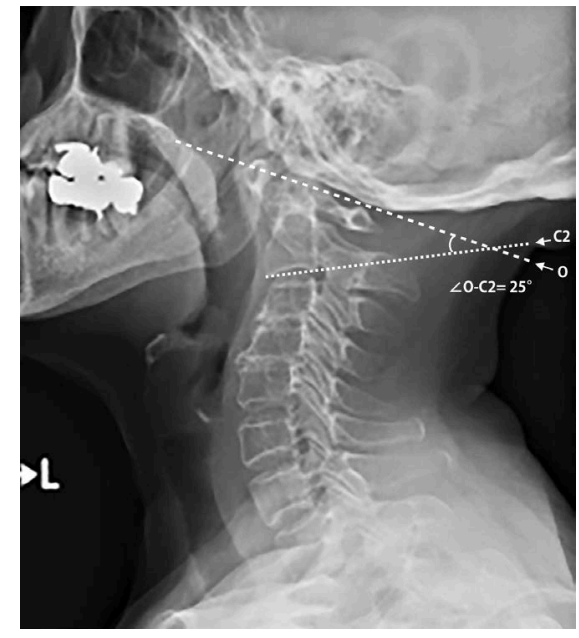

(a)

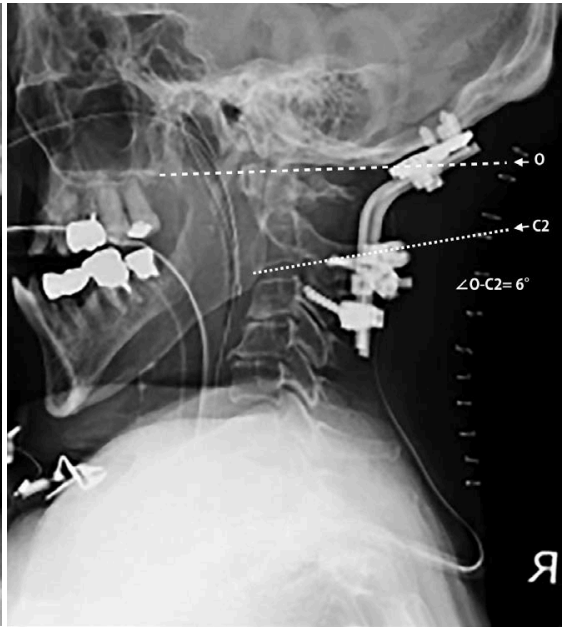

(b)

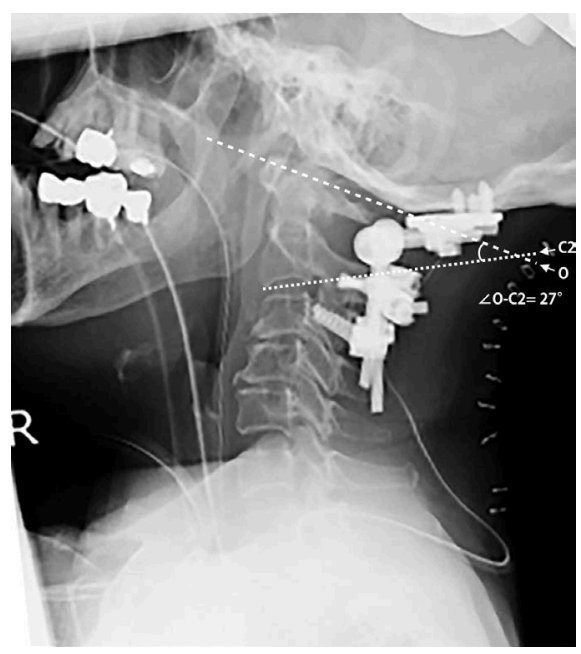

(c)

Figure 2. Lateral x-ray plane of the cervical spine; (a) preoperatively, (b) after initial surgery, (c) after second surgery.Line O: McGregor's line. Line C2: Extended line of the inferior endplate of the axis. The $\mathrm{O}-\mathrm{C} 2$ angle was $25^{\circ}$ preoperatively (a) and $6^{\circ}$ after initial surgery (b), and was corrected to $27^{\circ}$ after the second surgery (c).

fiberscope into the trachea. We believe this occurred due to the following reasons: difficulty in manipulating the tracheal intubation devices due to trismus and restricted range of motion in the cervical spine; difficulty in inserting the McGrath laryngoscope blade 3 (with a curvature of $20^{\circ}$ from the vertical axis) due to narrowing of the oral and pharyngeal cavities because of cervical flexion; and the angle allowing visualization of the tracheal entrance with fiberscope became too steep.

In the present case, we selected the McGrath laryngoscope for tracheal intubation for revision surgery based on a recommendation from the attending anesthetist, who suggested that we should use the same airway management method used in the initial surgery. Many studies have previously reported the use of tracheal intubation in patients with or suspected of having impaired stability in the cervical spine, which emphasized the importance of avoiding the risk of cervical 
spinal cord injury caused by tracheal intubation. As described by Hastings and Crosby et al., appropriate fixation of the cervical spine used during tracheal intubation can prevent serious neurological disorder(s) [11] [12]. According to the World Health Organization (WHO) and the guidelines of the Eastern Association for the Surgery of Trauma (EAST), use of manual or mechanical cervical immobilization is recommended in patients with head and neck injury undergoing tracheal intubation, with the aim of minimizing movement of the cervical spine [13] [14]. Lennarson and Gerling et al. stated that MILS, intended for protection of the cervical spinal cord, was a desirable technique in maintaining an immobile cervical spine because it was more effective in limiting extension of the cervical spine compared to a cervical collar [15] [16]. In contrast to these reports, Hirabayashi and Higashi et al. suggested that MILS could not ensure good visualization of the laryngeal anatomy, possibly resulting in difficult intubation [17] [18]. In the present case, tracheal intubation at the initial surgery was easily performed using AWS under MILS, which led to our decision that oral tracheal intubation would be possible using AWS or the McGrath laryngoscope, even in a patient with posterior occipitocervical fusion at the time of revision surgery.

During tracheal intubation, the majority of upper cervical movement occurs at the C1 - C4 levels [18] [19]. The head extension angle (angle variation from the horizontal position of the face [set at $0^{\circ}$ ] to the head and neck position obtaining the best view of the glottis via laryngoscope measured using goggle-goniometer [18]) during laryngoscopy using the Macintosh laryngoscope is reported to be $15^{\circ}$ [20]. The McGrath laryngoscope requires less head and neck motion during laryngoscopy compared with the Macintosh laryngoscope. Higashi et al. reported that the head extension angle required to obtain the best visual field via the McGrath laryngoscope is $9.9 \pm 2.8^{\circ}$ ( $6.6 \pm 2.8^{\circ}$ for AWS) [18]. They also cautioned that a certain degree of neck extension is needed to perform tracheal intubation, and that patients with cervical fusion have difficulty with the procedure using the McGrath laryngoscopy or AWS [18]. Thus, our first choice of the McGrath laryngoscope for this patient with extremely limited neck mobility after posterior occipitocervical fusion was the wrong decision.

The patient had a 25-year history of chronic RA, and there was a possibility that narrowing of the pharyngeal cavity had been present due to shortened neck length associated with dens recessus and joint destruction in the jaw [1] [6] [21]. Furthermore, there was a possibility of soft tissue proliferation, frequently observed in RA patients, which may have caused mucosal edema in the upper airway, leading to poor visual field via fiberscope [1] [6] [22]. In addition, surgical relief of the airway (i.e., tracheotomy) was expected to be difficult to perform due to the flexed neck position. In retrospect, we should have been more careful in selecting the methods of airway management for revision surgery.

Recent advances in technology have led to the development of various tracheal intubation devices. These devices appear to be effective and many are currently used in clinical practice; however, the optimal device for each patient must be selected by a clinician. Suppan et al. [23] conducted a review investigat- 
ing 16 tracheal intubation devices that can be used as alternatives to the Macintosh laryngoscope in patients with cervical spine immobilization. Among the five devices (including the McGrath laryngoscope and AWS) with sufficient data, only the Airtraq ${ }^{\mathrm{TM}}$ (Rush/Teleflex, Pennsylvania, U.S.) was associated with a significant reduction in both the rate of intubation failures at first attempt and in the time to successful intubation. The authors explained that the Airtraq has advantages in tracheal intubation in patients undergoing cervical fusion because its blade shape and optical component arrangement enable intubation in patients with insufficient mouth opening and/or head extension [23]. In the present case, we did not consider the use of supraglottic devices because the patient was undergoing surgery in a prone position. One may argue that we could have used the LMA Fastrack ${ }^{\mathrm{TM}}$ (Teleflex, Pennsylvania, U.S.) or the air-Q ${ }^{\circledR}$ (Mercury Medical, Florida, U.S.) for the patient because these devices enable intubation with the neck flexed [24], and that tracheal intubation via the lumen of these devices is possible. However, in a retrospective review involving 14,480 South-East Asian patients undergoing general anesthesia, Saito et al. identified four risk factors for difficult ventilation via a supraglottic airway device: male sex, age $>45$ years, short thyromental distance, and limited neck movement [25]. Clinicians should be aware that patients with a flexed neck, similar to the present case, incur a risk for developing difficult ventilation due to limited neck movement and/or short thyromental distance using a supraglottic device.

This study reconfirmed two important points through our experience with posterior occipitocervical fusion and anesthetic management for the present patient. First, regarding posterior occipitocervical fusion, the degree of cervical correction should be evaluated intraoperatively through confirmation of variation in the O-C2 angle, and this evaluation allows the prediction of postoperative dyspnea and/or dysphagia. Second, regarding anesthetic management, the extent of cervical spine immobilization and its effect on intubation conditions fundamentally differ between patients undergoing MILS and those who had undergone cervical fusion because MILS, intended to prevent movement of the cervical spine during tracheal intubation, cannot completely immobilize the cervical spine. This case report can provide useful information for physicians and anesthetists performing surgery and anesthetic management for cases similar to the present patient. To prepare for safe anesthesia and surgery, anesthetists must have sufficient knowledge about many tracheal intubation devices, including supraglottic devices, and prepare them in the operating rooms. Because it is important to select an appropriate device for each patient, skill, environment, and knowledge are essential.

\section{Conclusions}

We encountered a case of difficult intubation during the revision surgery in a patient with dysphagia after initial posterior occipitocervical fusion. Evaluation of the change in the O-C2 angle due to fixation is useful to predict complications, and is also useful as an index of narrowing in the oral and pharyngeal cav- 
ities. Clinicians should be careful when selecting airway management methods and tracheal intubation devices because the narrowing of oral and pharyngeal cavities associated with neck flexion after posterior occipito-cervical fusion may hinder the manipulation of tracheal intubation devices.

\section{References}

[1] Izeki, M., Neo, M., Takemoto, M., Fujibayashi, S., Ito, H., Nagai, K., et al. (2014) The O-C2 Angle Established at Occipito-Cervical Fusion Dictates the Patient's Destiny in Terms of Postoperative Dyspnea and/or Dysphagia. European Spine Journal, 23, 328-336. https://doi.org/10.1007/s00586-013-2963-6

[2] Haller, J.M., Iwanik, M. and Shen, F.H. (2011) Clinically Relevant Anatomy of High Anterior Cervical Approach. Spine, 36, 2116-2121. https://doi.org/10.1097/BRS.0b013e31820408af

[3] Lee, M.J., Bazaz, R., Furey, C.G. and Yoo, J. (2007) Risk Factors for Dysphagia after Anterior Cervical Spine Surgery: A Two-Year Prospective Cohort Study. Spine, 7, 141-147.

[4] Riley, L.H., Skolasky, R.L., Albert, T.J., Vaccaro, A.R. and Heller, J.G. (2005) Dysphagia after Anterior Cervical Decompression and Fusion: Prevalence and Risk Factors from a Longitudinal Cohort Study. Spine, 30, 2564-2569. https://doi.org/10.1097/01.brs.0000186317.86379.02

[5] Bazaz, R., Lee, M.J. and Yoo, J.U. (2002) Incidence of Dysphagia after Anterior Cervical Spine Surgery: A Prospective Study. Spine, 27, 2453-2458.

https://doi.org/10.1097/00007632-200211150-00007

[6] Tagawa, T., Akeda, K., Asanuma, Y., Miyabe, M., Arisaka, H., Furuya, M., et al. (2011) Upper Airway Obstruction Associated with Flexed Cervical Position after Posterior Occipito-Cervical Fusion. Journal of Anesthesia, 25, 120-122.

https://doi.org/10.1007/s00540-010-1069-0

[7] Yoshida, M., Neo, M., Fujibayashi, S. and Nakamura, T. (2007) Upper Airway Obstruction after Short Posterior Occipito-Cervical Fusion in a Flexed Position. Spine, 32, E267-E270. https://doi.org/10.1097/01.brs.0000259977.69726.6f

[8] Miyata, M., Neo, M., Fujibayashi, S., Takemoto, M. and Nakamura, T. (2009) O-C2 Angle as a Predictor of Dyspnea and/or Dysphagia after Occipitocervical Fusion. Spine, 34, 184-188. https://doi.org/10.1097/BRS.0b013e31818ff64e

[9] Lee, Y.H., Hsieh, P.F., Huang, H.H. and Chan, K.C. (2008) Upper Airway Obstruction after Cervical Spine Fusion Surgery: Role of Cervical Fixation Angle. Acta Anaesthesiologica Taiwanica, 46, 134-137.

[10] Dark, A. and Armstrong, T. (1999) Severe Postoperative Laryngeal Oedema Causing Total Airway Obstruction Immediately on Extubation. British Journal of Anaesthesia, 82, 644-646. https://doi.org/10.1093/bja/82.4.644

[11] Hastings, R.H. and Kelley, S.D. (1993) Neurologic Deterioration Associated with Airway Management in a Cervical Spine-Injured Patient. Anesthesiology, 78, 580583. https://doi.org/10.1097/00000542-199303000-00022

[12] Crosby, E.T. (2006) Airway Management in Adults after Cervical Spine Trauma. Anesthesiology, 104, 1293-1318. https://doi.org/10.1097/00000542-200606000-00026

[13] Mock, C., Lormand, J., Goossen, J., Joshipura, M. and Peden, M. (2004) Guidelines for Essential Trauma Care. World Health Organization, Geneva.

[14] Mayglothling, J., Duane, T.M., Gibbs, M., McCunn, M., Legome, E., Eastman, A.L., 
et al. (2012) Eastern Association for the Surgery of Trauma. Emergency Tracheal Intubation Immediately Following Traumatic Injury: The Eastern Association for the Surgery of Trauma Practice Management Guideline. Journal of Trauma and Acute Care Surgery, 73, S333-S340. https://doi.org/10.1097/TA.0b013e31827018a5

[15] Lennarson, P.J., Smith, D.W., Sawin, P.D., Todd, M.M., Sato, Y. and Traynelis, V.C. (2001) Cervical Spinal Motion during Intubation: Efficacy of Stabilization Maneuvers in the Setting of Complete Segmental Instability. Journal of Neurosurgery, 94, 265-270. https://doi.org/10.3171/spi.2001.94.2.0265

[16] Gerling, M.C., Davis, D.P., Hamilton, R.S., Morris, G.F., Vilke, G.M., Garfin, S.R., et al. (2000) Effects of Cervical Spine Immobilization Technique and Laryngoscope Blade Selection on an Unstable Cervical Spine in a Cadaver Model of Intubation. Annals of Emergency Medicine, 36, 293-300. https://doi.org/10.1067/mem.2000.109442

[17] Hirabayashi, Y., Fujita, A., Seo, N. and Sugimoto, H. (2007) Cervical Spine Movement during Laryngoscopy Using the Airway Scope Compared with the Macintosh Laryngoscope. Anaesthesia, 62, 1050-1055. https://doi.org/10.1111/j.1365-2044.2007.05188.x

[18] Higashi, K., Kita, S., Iwagaki, T., Sano, H., Aoyama, K. and Takenaka, I. (2014) Comparison of Head Extension during Laryngoscopy with the McGrath Laryngoscope and Airway Scope. The Journal of Japan Society for Clinical Anesthesia, 34, 821-827. https://doi.org/10.2199/jjsca.34.821

[19] Sawin, P.D., Todd, M.M., Traynelis, V.C., Farrell, S.B., Nader, A., Sato, Y., et al. (1996) Cervical Spine Motion with Direct Laryngoscopy and Orotracheal Intubation. An in Vivo Cinefluoroscopic Study of Subjects without Cervical Abnormality. Anesthesiology, 85, 26-36. https://doi.org/10.1097/00000542-199607000-00005

[20] Hastings, R.H. and Wood, P.R. (1994) Head Extension and Laryngeal View during Laryngoscopy with Cervical Spine Stabilization Maneuvers. Anesthesiology, 80, 825-831. https://doi.org/10.1097/00000542-199404000-00015

[21] Redlund-Johnell, I. (1988) Upper Airway Obstruction in Patients with Rheumatoid Arthritis and Temporomandibular Joint Destruction. Scandinavian Journal of Rheumatology, 17, 273-279. https://doi.org/10.3109/03009748809098796

[22] Keenan, M.A., Stiles, C.M. and Kaufman, R.L. (1983) Acquired Laryngeal Deviation Associated with Cervical Spine Disease in Erosive Polyarticular Arthritis. Use of the Fiberoptic Bronchoscope in Rheumatoid Disease. Anesthesiology, 58, 441-449. https://doi.org/10.1097/00000542-198305000-00009

[23] Suppan, L., Tramèr, M.R., Niquille, M., Grosgurin, O. and Marti, C. (2016) Alternative Intubation Techniques vs. Macintosh Laryngoscopy in Patients with Cervical Spine Immobilization: Systematic Review and Meta-Analysis of Randomized Controlled Trials. British Journal of Anaesthesia, 116, 27-36. https://doi.org/10.1093/bja/aev205

[24] Oishi, H., Yamada, M., Oishi, M., Shakunaga, K., Hirota, K. and Yamazaki, M. (2013) A Case of Upper Airway Obstruction Associated with Flexed Cervical Position after Posterior Occipito-Cervical Fusion: A Retrospective Radiographic Analysis by the O-C2 Angle. The Japanese Journal of Anesthesiology, 62, 1120-1123.

[25] Saito, T., Liu, W., Chew, S.T.H. and Ti, L.K. (2015) Incidence of and Risk Factors for Difficult Ventilation via a Supraglottic Airway Device in a Population of 14480 Patients from South-East Asia. Anaesthesia, 70, 1079-1083. 
Submit or recommend next manuscript to SCIRP and we will provide best service for you:

Accepting pre-submission inquiries through Email, Facebook, LinkedIn, Twitter, etc. A wide selection of journals (inclusive of 9 subjects, more than 200 journals)

Providing 24-hour high-quality service

User-friendly online submission system

Fair and swift peer-review system

Efficient typesetting and proofreading procedure

Display of the result of downloads and visits, as well as the number of cited articles Maximum dissemination of your research work

Submit your manuscript at: http://papersubmission.scirp.org/

Or contact ojanes@scirp.org 